\title{
Self Damaging Circumstances: An Exploration of Gender and the Vacuum Identity as They Pertain to Self-injury
}

\author{
Joseph Santangelo ${ }^{\mathrm{a}}$
}

This article explores the vacuum identity as it relates to self-injury and the relationship between gender and self-injury. The research done in this article is based on in depth interviews from ten participants from a small liberal arts college in the MidAtlantic region. Findings suggest that vacuum identity may be directly related to self-injury through: 1) forming a new identity as a self-injurer; or 2) to deal with the isolation felt by the vacuum identity. Findings also suggest that the link between women and self-injury might pertain to the distress women feel over conflicting societal gender definitions and maintaining their gender role in a public domain. This research may contribute to counseling and social work in real-life applications to better understand selfinjury as a phenomenon.

Keywords: vacuum identity, self-injury, gender, identity, depression

\section{Introduction}

Self-injury is a topic that has not been adequately researched, and seems to be growing increasingly relevant as the rates of self-injury in disenfranchised minorities is increasing (Latzman 2009). Currently $13-26 \%$ of all youth (age 18 and below) have self injured at one point and the numbers seem to be growing (Latzman 2009). This shows that, as a society, we must progressively address this issue, and the first step lies in better understanding the reasons behind this phenomenon, or under what circumstances selfinjury seems to occur. With that mindset, this research was conducted with the exploratory goal of learning more about self-injury in its relationship to gender, and vacuum identity.

The research takes an identity-centered, sociology-based approach for understanding self-injury as a phenomenon, and explores how one's thoughts about themselves are displayed through the physical manifestation of causing oneself intentional bodily harm through self bruising, hitting, cutting, scraping, burning, pulling out hair, etc. The research started with the observation that those struggling with self-injury seem to be dealing with great distress, and difficulty defining themselves in a societal context. Literature suggests that depression and the vacuum identity are linked (Ebaugh 1988), and depression and self-injury are linked (Adler and Adler 2005) yet there seems to be no research exploring a direct connection between the vacuum identity and self-injury.

The hopes of this research are to point out the gaps in sociological self-injury research and delve into the identities of those who self injure, to better understand what they are going through, how they feel about self-injury, and thus be able to more adequately provide a social and academic support system that can help deal with this issue.

\section{The Vacuum Identity and Depression}

The research done in this study was based upon previous studies that link vacuum identity, depression, locus of control and self-injury. The vacuum identity is a loss of identity and therefore a loss of association with society (Ebaugh 1988). Vacuum identity is associated with depression caused by the loss of a major role and the influence this has on one's interaction in a societal context (Ebaugh 1988). Thus, in a sense, the vacuum identity is partially a type of anomie, and creates a strong sense of depression (Ebaugh 1988). In fact even role loss without vacuum identity can cause depression and self-doubt (Drahota and Eitzen 1998). Yet vacuum identity still cropped up in self-injury discussions, such as on online forums. Some examples from online discussion boards include, "I am really lost here" and "I just feel lost and alone lately" ("What's your story?" 2011).

\section{Self-injury and Depression}

Self-injury has also been shown to be linked with depression, and in many cases depression is present in those who self injure (Adler and Adler 2005). Depression correlates with a lower sense of control in one's life; many times depressed individuals feel like they cannot do anything to escape their situation and feel a learned helplessness (Coyne and Thompson 2011). Self-injury is a way of dealing with this; it is not based on suicidal tendency as many previously believed, but rather serves as a way for individuals to control their emotional response (Adler and Adler 2005). Many self injurers find that their emotions and sense of despair and anxiety are overwhelming and self-injury serves as a way to release that emotional load in a solitary manner (Adler and Adler 2005).

\section{Self-injury, Sense of Control and Social Roles}

Self-injury is a way for one to control one's emotions in privacy instead of having breakdowns in public (Adler and Adler 2005). Many interviewed stated that they felt better after injuring themselves, and others would never know they were different from anyone else in society (Adler and Adler 2005). In Goffman's terms, these individuals are self-injuring backstage in order to present front stage in a controlled manner (Goffman 1959). People who self injure are on the outskirts of mainstream society, yet still view things from a societal perspective. Thus self-injury is a way of fitting into society, and a manner of avoiding the loss of social contact. It is a way to avoid becoming socially isolated, or trying to appear normal if one is already socially isolated. This is reminiscent of the despair associated with role loss and vacuum identity (Ebaugh 1988). 
Furthermore, other research shows that self-injury used to be a loner form of deviance and is now becoming community based due to online forums (Adler and Adler 2008). This could potentially mean that individuals who are self-injuring are looking to find a new role, thus addressing their loss of self that occurs with the vacuum identity (Adler and Adler 2008).

This research also focuses on certain aspects of one's identity that may influence the occurrence of a vacuum identity or self-injury as a behavior, mainly one's gender, of which females have reported higher instances of self-injury (Ross 2002),

\section{Social Status, Identity and Self-injury}

When considering gender and how it relates to selfinjury and vacuum identity one must consider how one's gender relates to sense of self (Thoits 1986). First we must realize that one's gender influences the importance of roles, and that gender itself is made up of specific roles (Thoits, 1986). Certain roles are seen as more important based on whether or not those roles are stereotypically expected of one's gender identity (Thoits 1986). For example, women feel more distress than men about their roles in the public work arena because these are roles which women do not occupy according to traditional gender roles (Thoits 1986). The role of being a woman itself influences one's identity. Since one's experience shapes the way they interpret their roles, then some might interpret the role of being a woman to mean being thin and beautiful, and/or other similar societal-enforced definitions of "woman". Thus one might temporarily feel they have improperly performed the role of woman or experience a vacuum identity if they do not view themselves as beautiful or thin, and may find self-injury as a means of controlling their body (and identity).

It is also possible that women might feel more stress and have a harder time coping with stress than men because they are traditionally given a lower status in society (Pearlin 1981). Some women might feel a loss of control because of society's unattainable beauty standards, with self-injury being a way of coping with this societal pressure. Some women might devalue their body as a method of coping with this stress, even separating their bodies from their identities, so that selfinjury is a less personal experience and is not seen as a method of harming "oneself". In fact disenfranchised groups seem to have higher rates of self-injury in general, with the demographic of African American males growing in rates of self-injury (Latzman 2009). Children from less privileged socioeconomic backgrounds are also more likely to selfinjure, which indicates that lack of privilege is linked with self-injury (Wenz 1979). These are all ways in which gender may influence one's identity and vacuum identity and selfinjury.

The two concepts of vacuum identity and self-injury seem to be linked in various ways. However there is no current research about how the vacuum identity and selfinjuring are directly related. It would seem that this potential link deserves more exploration and my research plans to do just that by seeing if individuals who have self injured were experiencing vacuum identity during that time.

Although other issues, such as eating disorders (Favazza 2010) and sexual assault (Alexander, 2004) are also linked to self-injury, the identity of a self-injurer is an under-researched contributing factor to self-injury, and thus the focus of my research.

\section{Methods}

The research conducted in my survey is of an exploratory qualitative nature. In order to collect data, I conducted in depth interviews with ten participants regarding their role changes, perception of gender and sense of self, and circumstances in which they self-injure. I recruited participants by sending an e-mail to all students of a small liberal arts college in a rural, Mid Atlantic area.

Potential participants were screened to meet the following criteria: current male or female college students; age 18-24; and have self injured (including cutting, burning, bruising, etc.) at some point in the past two years before the study. Ten participants showed continued interest, and all ten of these interviews occurred in small, private, sound proof rooms on campus. This ensured that on campus counseling would be available for those who might need it, and corresponded with an emergency plan established before the interviews began. IRB approval was received before any interviews took place.

Those who participated in the study were all college students and varied in race, gender, and age among other things. See table 1 below for additional demographic data:

Table 1: Demographic data*

\begin{tabular}{ll}
\hline Gender identification & Percent \\
\hline Male & $10 \%$ \\
\hline Female & $90 \%$ \\
\hline Race & $80 \%$ \\
\hline White & $0 \%$ \\
\hline African-American & $10 \%$ \\
\hline Hispanic & $0 \%$ \\
\hline Asian & $10 \%$ \\
\hline Other & \\
\hline Year in school & $30 \%$ \\
\hline First-year & $60 \%$ \\
\hline Sophomore & $0 \%$ \\
\hline Junior & $10 \%$ \\
\hline Senior & \\
\hline Type of self-injury & $90 \%$ \\
\hline Cutting & $20 \%$ \\
\hline Bruising & $10 \%$ \\
\hline Scraping & $20 \%$ \\
\hline Pulling hair & $10 \%$ \\
\hline Picking & $30 \%$ \\
\hline Hitting & $20 \%$ \\
\hline Length of time since last self-injury & \\
\hline Within the week & $30 \%$ \\
\hline Within the month & $20 \%$ \\
\hline Within 2 months & \\
\hline Within 6 months & \\
\hline & \\
\hline
\end{tabular}

*Participants 5 and 8 never explicitly stated when they last self injured. Type of Self-injury adds up to more than $100 \%$ as participants can self injure in multiple ways, thus are counted more than once. 
Before starting the interview, I administered informed consent to conduct the interview and audio-tape it. Upon the interview's completion I gave a handout to all participants on information about the college's counseling center. The interview consisted of eighteen open ended questions. These questions explored how the participant interpreted their gender in a societal context, how they felt about their selfinjury and how they perceived others to feel about it, and how they defined themselves and their identities during or after they self injured. An example of this would be, "How would you describe yourself when you first started self-injuring?"

After the interviews were complete, I transcribed them in full and analyzed the data through a series of coding methods, focusing on two main themes: vacuum identity; the relationship between gender and self-injury. I also charted all themes by participant to track patterns across participants. The analysis ended in compounding these analyses into a results section, and pulling quotations from the interviews that illustrated the recurrent themes.

\section{Results}

Two main topics emerged from my interviews: 1) The idea of the vacuum identity as it relates to self-injury and 2) the relationship between gender and self-injury. However these relationships were slightly different than expected.

\section{Vacuum Identity and Self-Injury}

Five out of ten participants showed signs of having a vacuum identity through their definition of their identity at the time when they first started self-injuring. Thus it seems that there might be a direct connection between self-injury and vacuum identity. This connection manifested itself in two ways: feelings of isolation and a way to regain one's identity.

\section{Self-Injury, Isolation, and the "Who Am I?" Question.}

Some participants felt isolated and did not seem to know who they were in a societal context. This is not to say that the interviewees had no societal roles, but that they felt like they did not belong anywhere, and their identity did not meet societal standards. John (white, male sophomore) talked about how he felt like he had no friends, could not relate to his parents or siblings, and how this made him feel misunderstood and different to the point of not being able to relate to others. When describing these feelings he stated, "I was isolated, I was so isolated."

This notion of anomie and extreme isolation does not seem to lower the self-worth of these individuals, or internalize that their loneliness is their own fault; rather it makes them examine their identities and question what about them makes it so that no one in the world seems to understand them or even relate to them. This can be seen in the interviews in Christina, John, and Jackie. Christina, a white, female first year, states, "I wouldn't say I was attention seeking, but was desperate to receive approval."

And John, a white male sophomore states that he felt, isolated, "I felt as if I were doing things I did not want to be doing." Jackie, a timid, first year also talks about how she feels and how her isolation seems to be internalized:

"I just felt really horrible, like I didn't deserve things and I was just like in my room, alone, really upset, and I just. I think I was crying and I just hit myself because, to like let out some of the pain."

Both Jackie and John expressed that they internalized this feeling of worthlessness or felt like no one cared, which made them no longer care about their bodies or themselves. This led to feelings of self-hatred and confused notions of who they were, and they injured because they thought they deserved it, as a way of punishing themselves for being unlikable and alone. John states that,

"Self-injury is not out of a suicidal place but sincerely believing I deserve what I am doing to myself. It appeases guilt."

It seemed to be a method of coping with feelings of social and emotional anomie triggered by a vacuum identity, rather than the void of identity directly.

\section{Self-Injury as "Regaining Identity"}

The second way that vacuum identity seemed to relate to self-injury was seen in the case of Paula, a Latina senior. Paula described a vacuum identity that was partially due to ethnic heritage as well as self-injury as a way to gain an identity. Paula stated that didn't really fit in, and showed obvious signs of a vacuum identity:

"I just remember going to a Christian school during high school, and feeling like I didn't fit in with anyone. And I was adopted, so at home at that point in my life I was wondering about my [Latina] heritage, and felt like I didn't know anything about that part of me."

In this way Paula showed that she felt isolated and lost in defining herself, and felt like she could not relate to others in school, much like how the aforementioned participants felt. However she then seemed to insinuate that she started cutting because she felt alone and thought that other girls her age were doing so, as if it was a last ditch attempt to fit in:

"At around that time I read an article in a magazine or something about how all the girls my age were cutting, so I just tried it to see what it was like."

Although this did not seem to be the reason she kept selfinjuring, as it became a coping strategy in its own right, it is interesting and important to take into account how Paula's perception of what other girls her age were doing influenced her behavior. She stated that she decided to try it after reading an article that said that other girls her age were doing this frequently, and that she previously did not fit in with anyone at her school. Thus it could be suggested that Paula was trying to redefine herself in way that would allow her to relate to girls her age. She felt a vacuum identity, and did not know who she was, and at the same time felt like she could not relate to anyone at her school. So Paula adopted a new identity, as someone who self injures, that she perceived other girls her age to also have. Thus by establishing some part of her identity that she thought was relatable to other girls her age, she could adopt a role that could potentially fill her vacuum identity and find a way to make new friends. In this way vacuum identity relates to self and gender, as Paula used self-injury as a potential means of coping. Yet it was the perception of what was normal for her gender and age cohort that suggested self-injuring in the first place, and it was Paula's want to be accepted into that cohort and not face the anomie that was part of her vacuum identity, that made her decide to self-injure for the first time. 


\section{Gender Identity and Self-Injury}

The second theme seen in the research conducted dealt with gender. Originally it was suspected that gender would influence the frequency of self-injury because of women's disenfranchised place in society; specifically, it was believed that when women were experiencing role void, they would have less social venues to find new roles in. This is based on the traditional view of women as present in the household while men were free to establish roles both inside and outside of the household. Upon reviewing the data, this hypothesis was not supported. Instead, other connections emerged between gender and self-injury.

Many female participants seemed to express confusion over their societal gender roles. Female participants seemed to define female gender roles in two ways. Either 1) women are meant to be emotional, and take care of the family or 2) women have to be strong, contribute to the household income, and not be emotional in public. What is interesting is that many interviewees identified with both of these definitions; women had to be both strong and emotional, and had to take care of the family and bring home money. These conflicting gender roles caused frustration and desperation for participants. This was a major theme in the research as four out of nine female participants held this contradictory definition of what it meant to be a woman. This can be seen in Lindsay's quote:

"Society views women still, sadly, as housewives who I guess in this day and age they have to be tough but they still have to be giving and they have to be loving without being pushovers. And it's just actually gotten worse because you have to be one but you have to be independent at the same time."

This irreconcilable contradiction seems to add distress as many individuals hold themselves to standards that don't coincide with the standards they view society to have. Thus when they cave to society's expectations they are upset with themselves. But even when they do not, they constantly feel like they are at odds with the societal definition of woman, because they cannot be all of these different components at once. Betsy, a white sophomore, illustrates this when talking about how gender related to her self-injury:

"I would say I was probably not being a very good woman. Um I was aggressive, not docile in any way shape or form. I think of the stereotypical 50s housewife. You know, like sweep it under the rug, and I was way too out of control for anything remotely close to sweeping...I guess if I thought of how I was being a woman in terms of self-injuring, I would say I was not being a good woman."

Furthermore many women in the study explained that they self injured to control a situation, so that they wouldn't publicly lose control, or show their emotions later. It was originally thought that self injurers did so for a sense of control over their bodies, as society has high body standards for women, but this does not seem to be the stressor. It seems like the participants are more distressed at the high standard of what a woman must be, and this strict code makes them feel constantly overwhelmed, to the point where self-injury is a way for them to control their emotions, so that they can act composed in public. This control of emotions can be seen in an excerpt from Kelly's interview:
"I felt really overwhelmed...I didn't feel bad about the self-injury. I mean this is what I need to do: to cut myself so I can recover [from the overwhelmed feeling]".

Thus Kelly, through self-injury, is able to recover from the overwhelming emotions she is feeling. The reason for this relates to participants' views of gender. According to the interviews conducted, women (defined by societal expectations) don't "freak out" in public. To make sure they perform their roles of woman correctly, or even members of society that are not looked down upon, the participants seem to control their emotions behind the scenes, and cut where no one can see, so that they do not show these emotions in public. The fact that these participants do not want others to know about their backstage means of controlling their emotions can be seen by many participants who expressed that they self injured in places they thought no one else could see. Betsy expresses the desire for no one to find out when she says:

"The whole premise for me for any kind of self-injury is that you do not let other people see what is going on."

In this sense self injurers have complete control over how people view them, thus self-injury seems to be about the illusion of control over one's self. This research shows that it may not be about one's body, but instead about controlling one's emotions. This can be seen in Betsy's explanation of why she self injures:

"When things become so overwhelming or even like hooking onto people mentally or emotionally, it is my way of physically drawing my attention to something else...If I don't feel like I'm in complete control of myself at the moment it is my way of going against that and making myself think of something else for the time...I was going to cry about something, and I'm not a crier, I don't do that, and I think I was so mad at myself for getting to that point of mental anguish, that I needed to think about something else, so I tried self-injuring."

This occurs because participants are worried that if they don't actively control their emotions in private, they will not be able to do so in public, and will be judged for it. Thus this conflicting definition of gender contributes to self-injury by adding distress, and by allowing self-injury to be a way to cope with this distress and these conflicting definitions of gender.

We can see through this that even in the case of selfinjury, gender plays an important role, though in different ways than previously expected.

\section{Disconfirming Evidence}

It cannot be assumed that these themes are the only reason individuals self injure. If anything, these interviews have shown the complexity of emotions and reasons behind self-injury. Several participants even stated that to generalize about self injurers was wrong, as this behavior is not reserved for any group of people or any one reason entirely. Alyssa talks a lot about how her eating disorder influenced her to self-injure stating,

"When I was recovering from my eating disorder...that's when I actually started to self-harm, which is really normal for people recovering."

And Ramona who also mentions presence of mental disorders in her experience with self-injury, states: 
"Something common among people who self harm is that they have a lot of mental disorders going on."

Almost all participants showed signs of depression, but only half displayed signs of vacuum identity, showing that depression without vacuum identity also is may influence self-injury. This seemed to be the case for Pippy, who stated that she was depressed when discussing the first time she self injured, but went on to say that "There were a lot of times I felt confused about myself, but never...completely lost" showing that she did not have a vacuum identity.

Other participants claimed that self-injuring was a way to deal with sadness caused by role loss or feelings of loneliness, but did not seem to exhibit a vacuum identity. With these participants, self-injury seemed to be less a sense of self punishment and more a way of coping with the sadness, so that it didn't overwhelm them. These instances cannot be chalked up to vacuum identity, as they deal more with selfcontrol; self-injury seemed to be a way to control or subdue feelings of depression and worthlessness or un-likability rather than a sense of punishment for a lack of identity or social acceptance.

\section{Discussion}

There are many parallels between my study's results and existing literature. The results support previous thoughts on how gender relates to self-injury (Adler and Adler 2005). The research may also show a direct link between the vacuum identity and self-injury, a topic previously not researched.

As the results show, the vacuum identity may relate to self-injury. The literature gave a strong argument for a link between these two phenomenons, with vacuum identity being linked to depression (Ebaugh 1988) and depression being linked to self-injury (Adler and Adler 2005). My current research has shown that vacuum identity relates to self-injury through an individual responding to the sense of anomie they feel in a self-injurious manner or through the desire to create a new identity through becoming a self-injurer. The literature review stated that the main reasons for self-injuring entailed regaining a sense of self control (Adler and Adler 2005) as well as coping with depression through self harming. These reasons all appeared in the interviews conducted, with seven participants specifically mentioning that their self-injury made them feel a sense of control over their lives.

However these were not the only reasons individuals gave for self-injuring, and there seems to be no research exploring self-identity as role gain in the case of someone suffering from vacuum identity such as in the case of Paula. There is also a lot of research on depression and self-injury (Favazza 2010) and how individuals self injure to punish themselves for a variety of reasons (Favazza 2010) but this study revealed that individuals who self injure may not just be depressed. The vacuum identity seems to be present here and the self-hatred developed by those who self injure may have to do more with this than with depression. Individuals seem to be punishing themselves or self-injuring specifically because they have internalized the loneliness and confusion of a vacuum identity; they have internalized their sense of anomie as their own fault. This is an interesting situation as depression is present here as well and the emotions and explanations for self-injury may stem from depression, a vacuum identity, or a mixture of both. To discover more about this relationship, more research should be done specifically exploring the identity of those who have recently self injured. This research should be focused on whether individuals selfinjuring have vacuum identity and if they do, how the lack of sense of self relates to their self-injury. It would expand on the research done in this study with more participants and more in depth interviews.

The research done should also pay attention to mental disorders and how they play into depression and vacuum identity. Rates of self-injury are higher among those with mental disorders, and various mental disorders are known to be related to depression (Favazza 2010). Research must be done to attempt to pull apart what connects depression, vacuum identity and other mental disorders as these three phenomena seem to be connected with self-injury. This is difficult, as they are also very connected to each other that it may be difficult to tease out what of the three is really contributing to self-injury and what is not. Perhaps in order to better understand this, research focused on how mental disorders relates to the vacuum identity should also be conducted, to better understand how they interact and lead to self-injury.

In the case of how gender relates to self-injury, the literature (Thoits 1986) seems at odds with what was discovered in this study. Previous research suggests that females were more likely to self-injure for two reasons: a lack of social outlets in which to cope with distress they might endure (Thoits 2011) and a learned helplessness from a patriarchal society that constantly enforces body expectations upon women. It was thought that self-injuring would be reclamation of control over one's body, as women might feel like they have no control over their own bodily expectations. What was found in this study was far more interesting. It seemed that the elevated rates of self-injury in women are caused by societal factors, but perhaps not the ones originally thought. Women in this study seemed to show distress about societal expectations and their contradictory nature. At this time women seem to be defining the role of female in both a modern and historical perspective; that is to say that women are frustrated because they feel the need to be a good mother, nurturing and happy and calm like a 1950s housewife, while at the same time making money, being strong and being independent like a modern corporate businesswoman.

This dichotomy is stressful, and it seems to the participants in the study, like there is no winning in their portrayal of the female role. They can either be the prude or the slut, bitchy or stupid, too emotional or not emotional enough. This manifests itself in self-injury as women have to strictly define what femininity means to them and many times to defy these societal expectations women wish to show no vulnerability in the public arena. Adler and Adler talk about how self-injury is a mechanism for unloading emotional stress in a private manner (Adler and Adler 2005). This reasoning seems pretty accurate in the context of this study as self-injury seems to be a way to control ones distress or feelings of being overwhelmed.

Goffman focused on the human identity as a series of roles we must perform (Goffman 1959). In the case of this study, we see women self-injuring backstage; in private where no one else can see, so that they can continue to perform their role of woman in public without emotional hindrance. Thus self-injuring is not only a marker of controlling ones 
emotions, but perhaps more importantly, controlling one's social image. In this context we can see that self-injury may be reclamation of oneself from societal pressures of being a woman by regaining a feeling of control over one's self image and self-portrayal. At the same time these women continue adhering to societal pressures by self-injuring privately to deal with their frustration and overwhelming pressure. This is a fascinating dynamic, as we see that social expectations both manipulate and can be manipulated by one's performance of self.

\section{Conclusion}

This study has separated gender, vacuum identity and social institutions into mutually exclusive categories for the sake of better delving into the separate facets of the identities of self injurers. However, no facet of identity is mutually exclusive and all of these parts of one's identity comingle and interact in ways we are only beginning to understand. Furthermore, this research has attempted to draw meaning from interviews with individuals who have self injured, but these exploratory conclusions cannot be generalized to the larger population of self-injurers because the sample was not representative. That being said, it is vital to conduct further research on gender and the vacuum identity in relation to selfinjury and attempt to distinguish patterns and themes in those who self injure so that we can develop better understanding of self-injury as a behavior and better relate to and be able to help those who self injure. Education is the first step to bettering a situation, and self-injury occurs far too often for it to be ignored any longer. This research helps us better understand self-injury, so that those who self injure can be understood and supported rather than judged and further ostracized.

\section{References}

Adler, P., \& Adler, P. (2005). Self Injurers as Loners: The Social Organization of Solitary Deviance. Deviant Behavior, 26, 345-378.

No Authors. (2008). The Cyber Worlds of Self-Injurers: Deviant Communities, Relationships, and Selves. Symbolic Interaction, 31, 33-56.

Alexander, N., \& Clare, L. (2004). You Still Feel Different: The Experience and Meaning of Women's Self-injury in the Context of a Lesbian or Bisexual Identity. Journal of Community \& Applied Social Psychology, 14, 70-84.
Center for Disease Control. (2012). Suicide and Self Inflicted Injury Suicide Statistics, 2011. Washington, DC: Centers for Disease Control and Prevention. Retrieved from http://www.cdc.gov/nchs/fastats/suicide.htm.

Coyne, L., \& Thompson, A. (2011). Maternal Depression, Locus of Control, and Emotion Regulatory Strategy as Predictors of Preschoolers' Internalizing Problems. Journal of Child \& Family Studies, 20, 873-883.

Drahota \& Eitzen. (1998). The Role Exit of Professional Athletes. Sociology of Sport Journal, 15, 263-278

Ebaugh, H.R.F. (1988). Becoming An Ex: The Process of Role Exit. Chicago, IL: University of Chicago Press.

Favazza, A.R., DeRosear L. \&Conterio, K. (2010). SelfMutilation and Eating Disorders. Suicide and Life Threatening Behavior. 19, 352-361

Goffman, E. (1959). The Presentation of Self in Everyday Life. New York: Anchor Books.

Latzman, R.D., Gratz, K.L., Young, J., Heiden, L.J., Damon, J.D., Hight, T.L. (2009). Self-Injurious Thoughts and Behaviors Among Youth in an Underserved Area of the Southern United States: Exploring the Moderating Roles of Gender, Racial/Ethnic Background, and School-Level. Journal of Youth and Adolescence, 39, 270-280.

Pearlin, L.I., Lieberman, M.A., Menaghan, E.G., \& Mullan, J.T. (1981). The Stress Process. Journal of Health and Social Behavior.

No Authors. (2011) What's your Story. Psychforums.com, Retrieved from http://www.psychforums.com/cutting-selfinjury/topic66124-90.html.

Ross, S., \& Heath, N. (2002). A Study of the Frequency of Self-Mutilation in a Community Sample of Adolescents. Journal of Youth and Adolescence, 31, 67-77

Stryker, S. (1980). Symbolic Interactionism: A Social Sturctural Version. California: University of California Press.

Thoits, P.A. (1986). Multiple Identities: Examining Gender and Marital Status Differences in Distress. American Sociological Review, 51, 259-272.

No Authors. (1992). Identity Structures and Psychological Well-Being: Gender and Marital Status Comparisons. Social Psychology Quarterly, 55, 236-256.

No Authors. (2011). Mechanisms Linking Social Ties and Support to Physical and Mental Health. Journal of Health and Social Behavior, 52, 145-161.

Wenz, F.V. (1979). Self-injury behavior, economic status and the family anomie syndrome among adolescents. Adolescence, 54, 387-398. 